\title{
The Economic Perspective of Food Poverty and (In)security: An Analytical Approach to Measuring and Estimation in Italy
}

\author{
Stefano Marchetti ${ }^{1}$ (D) $\cdot$ Luca Secondi ${ }^{2}$ (D)
}

Accepted: 28 December 2021 / Published online: 5 January 2022

(c) The Author(s), under exclusive licence to Springer Nature B.V. 2022

\begin{abstract}
The UN Sustainable Development Goals have set clear targets on global poverty, hunger and malnutrition to be achieved by 2030, which have prompted academics and policymakers to identify useful strategies and drivers. Moreover, the COVID19 pandemic has exacerbated inequalities at national and sub-national levels thus hampering the achievement of these goals. On considering the multifaceted nature of poverty, a recent research strand focuses on food poverty and insecurity issues in terms of economic access to food and healthy diet consumption, with moderate and extreme food insecurity affecting almost 9\% of the population in Europe and North America. This paper aims to analyse food poverty and insecurity at regional level in Italy. Using micro-data from the Italian Household Budget Survey carried out by ISTAT, an analytical approach was proposed to define and measure the different degree of food poverty and insecurity. Moreover, to obtain insights into whether food poverty and insecurity can afford population healthy nutrition, inequality of the distributions of food expenditure categories are estimated. The results provided us with information on other important aspects of the poverty. Indeed, in Italy individuals who are at-risk-of-food-poverty or food insecure amount to $22.3 \%$ of the entire population. Furthermore, the at-risk-of-food-poverty-rate varies at regional level from $14.6 \%$ (Umbria) to $29.6 \%$ (Abruzzo), with high levels of food consumption inequalities observed above all for vegetables, meat and fish. All these issues could help policy makers to define economic intervention policies aimed at reducing social exclusion and achieving more equitable and sustainable living conditions for the entire population.
\end{abstract}

Keywords Economic access to food - SDG 1 - SDG 2 - Food poverty · Food insecurity · Italian household budget survey

Luca Secondi

secondi@unitus.it

Stefano Marchetti

stefano.marchetti@unipi.it

1 Department of Economics and Management, University of Pisa, Via Ridolfi 10, 56124 Pisa, Italy

2 Department for Innovation in Biological, University of Tuscia, Agro-Food and Forest Systems (DIBAF), Via S.C. De Lellis, snc, 01100 Viterbo, Italy 


\section{Introduction}

Reducing poverty and related economic and multidimensional inequalities among and within countries has captured international attention for several years, which has recently become stronger due to the onset of COVID-19 pandemic in both developing and developed countries (Bidisha et al., 2021; Pereira \& Oliveira, 2020).

In 2015, the Sustainable Development Goals (SDGs) established by the United Nations (UN) have served as a call to action for world nations to end poverty, protect the planet and ensure economic, social and environmental sustainability by 2030. SDG 2 foresees the reduction of food insecurity by reducing chronic hunger-defined as situation that exists when people lack access to sufficient amounts of nutritious food for an active and healthy life as measured by the Prevalence of Undernourishment (PoU), in accordance with SDG Indicator 2.1.1.

The ability of households or individuals to access basic needs and especially food is one of the most important aspects of poverty for assessing and evaluating inequalities. Indeed, the right to food was recognized as a fundamental human right by the UN Declaration of Human Rights in 1948 thus linking poverty with health and social outcomes.

Food poverty and food insecurity may appear to refer exclusively to developing countries, but in actual fact it is a phenomenon that was also present in developed and affluent countries (Hossain et al., 2021; Zaçe et al., 2021) including Europe (Beacom et al., 2020a; Penne \& Goedemé, 2021) and more generally OECD countries (Boarini \& Mira d'Ercole, 2006), even before the outbreak of Covid-19 pandemic.

According to the Food and Agriculture Organization (FAO), over the last two years food insecurity has risen significantly since 750 million people $(9.7 \%)$ have been exposed to severe levels of food insecurity and more than 2 billion people do not have regular access to sufficient, safe and nutritious food. Moreover, moderate and severe food insecurity levels have also affected almost $9 \%$ of the population in Europe and North America (Carrillo-Álvarez et al., 2021; FAO 2020, 2021). According to CarrilloÁlvarez et al. (2021), more detailed territorial analyses have shown that the prevalence of food insecurity in specific populations of these territories could have reached values of 10-15\% (Gundersen et al., 2021; Loopstra et al., 2019; Penne \& Goedemé, 2021; Pool \& Dooris, 2021).

In this perspective, the lack of access to a nutritious and healthy diet caused by insufficient purchasing power is the main research topic of food insecurity in developed welfare states as well as the consequences of undernourishment, which are both targets established by the SDG indicator 2.1.1.

According to Campiglio and Rovati (2009), the paradox of "scarcity in abundance" takes on a specific connotation in the case of food insecurity and poverty, which are significantly widespread in most developed countries where a percentage of the population facing food shortages coexists with food waste (Secondi et al., 2015), overproduction and abundant food availability (Stringer, 2016).

Since Italy has one of the highest percentages of population At Risk of Poverty (ARoP) in Europe, we think relevant to carry out a study focused on the issues of food poverty and food insecurity also for the Italian individuals and households at the territorial (sub-national) level.

The difficulties of the Italian population in sustaining food expenses have long been monitored by official statistical surveys, especially using subjective indicators, while there has been a lack of information and statistical measures on 'food poverty' and 
'food insecurity' which could be obtained from the microdata collected in consumption surveys, as already adopted by other European countries (Beacom et al., 2020a; Healy, 2019).

It is important to note that Italy made a significant step forward in 2009 with the introduction of the new absolute poverty measurement technique developed by the Italian National Institute of Statistics (ISTAT) that adopted it as an official measure (Cutillo et al., 2020) and for which the food component was accurately estimated taking into account the nutritional needs and the different cost of living in different types of municipalities and regions. However, that work was costly and time consuming, which until now has not been repeated.

Nevertheless, to implement a study on food poverty and food insecurity it is possible to exploit the potential of the Household Budget Survey (HBS), since foods-detailed data are collected on the different types of foods purchased by households.

The aim of this paper is twofold. First, to propose an analytical approach focused on the sequential and necessary analyses to be implemented to accurately measure economic food poverty, food insecurity and the related inequalities among households at subnational level, thus providing policy makers with finer measures (Alaimo \& Maggino, 2020; Secondi, 2021). Second, to carry out estimation of food poverty and food insecurity for Italy. The estimations, obtained by using the 2017 HBS wave, were mainly carried out at regional level, because the HBS sample size allows to obtain direct reliable estimates only for the regions.

The rest of the paper is structured as follows. Section 2 describes the main aspects of the Italian HBS. Section 3 presents the framework of the analyses. After having shortly presented some background information on the topic and the interconnections between the economic poverty, food poverty and insecurity, the measures used for the analyses are presented. Section 4 presents and discusses the results of the estimations obtained and of the analyses carried out. In Sect. 5 some concluding remarks are drawn and a range of potential uses of the proposed approach are described.

\section{Data Used: Main Characteristics of the HBS}

As regards the data used for the measure and analysis of economic poverty, much research has been carried out on the opportunity of using household consumption expenditure or income (Chaudhuri \& Ravallion, 1994; Deaton, 1997). In short, the problem of using income as a measure of welfare is that the poor may dissave significantly, upper income households tend to understate their income and the income measure may not consider nonremunerative activities of the households, such as subsistence farming. On the other hand, consumption expenditure is a better proxy of material living standard with short-term fluctuation smoothing out and with a higher data quality than microdata for income, above all toward the bottom of the income distribution (Meyer \& Sullivan, 2011; Brewer \& O'Dea, 2012) since "questions about consumption are usually seen as less sensitive than questions about income" (UNECE, 2017). However, this discussion is not strictly relevant for the measure of food poverty and food insecurity, because adequate data on food consumption and expenditures are obtained only from the Household Budget Surveys-HBS (Eurostat, 2020), therefore our estimates and analyses are based on the Italian HBS carried out in 2017 by ISTAT. 
The Italian HBS is conducted continuously, every month throughout the year. The sampling design is partly single-stage and partly two-stage, with stratification of primary sampling units; primary sampling units are municipalities, elementary sampling units are households residing in the municipalities. Annual theoretical national sample was approximately 19,500 households (about 1630 households per month), whereas annual actual sample was about 17,000 households. In 2017, the selected municipalities were 491 (47 participating in the survey all months and 444 participating once a quarter). The sample size was composed of 16,947 households and allows for reliable estimates at regional level (NUTS 2 level, according to the EU nomenclature).

The focus of the HBS is represented by all expenditures incurred by the resident households to purchase goods and services devoted to household consumption exclusively.

The data collected on the expenses refers to 303 categories according to the European Classification of Individual Consumption by Purpose (ECOICOP), which can be aggregated at higher levels into classes and divisions.

In our study we used the microdata file for research purposes provided by ISTAT. The data of our interest and we have used to obtain the measures and analysis proposed in the next section refer to the average monthly household expenditure for the total Food and nonalcoholic beverages (division 01) and for the following 11 classes: (i) Bread and cereals; (ii) Meat; (iii) Fish and seafood; (iv) Milk, cheese and eggs; (v) Oils and fats; (vi) Fruit; (vii) Vegetables; (viii) Sugar, jam, honey, chocolate and confectionery; (ix) Food products not elsewhere classified (n.e.c.); (x) Coffee, tea and cocoa; (xi) Mineral waters, soft drinks, fruit and vegetable juices.

\section{The Proposed Analytical Approach}

\subsection{Background Information on the Topic and Interconnections Between the Economic Poverty, Food Poverty and Insecurity}

Poverty and food insecurity are intrinsically linked as poor households often lack the resources required to access sufficient nutritious food to live an active and healthy life (Hjelm et al., 2016; p. 275).

The strict relationship between poverty and access to food has led to international consensus established at the 1996 World Food Summit (World Food Summit, 1996) by defining the four pillars of food security (Upton et al., 2016), namely food access, availability, food use and stability (FAO, 2006).

Within this framework, at international level SDG 10 aims at reducing inequalities within and among countries, including those related to economic, representation, migration and development assistance issues. Moreover, SDG 1 focuses specifically on eradicating poverty in all its forms by assisting the most vulnerable individuals, increasing basic resources and services and supporting the communities affected by conflict and climaterelated disaster.

However, despite positive signs such as reducing relative income inequalities in some countries and assigning preferential trade status to lower-income countries, inequalities still exist with approximately $10 \%$ of the total world population struggling to fulfil the most basic needs and therefore living in extreme poverty conditions (UN, 2020). Indeed, even before COVID-19, baseline projections suggested that approximately $6 \%$ of the global population would still be living in extreme poverty in 2030 thus missing the established SDG 
targets. This forecasting was exceeded due to the COVID-19 pandemic which additionally pushed over 70 million people worldwide into extreme poverty in 2020 (UN, 2020) with the total rising to as many as 150 million by 2021 (World Bank, 2021).

As highlighted by Penne and Goedemé (2021) and Cantillon et al. (2019) even if all EU member states provided minimum income support for the working age population, poverty still remains a challenge since a large percentage of inhabitants cannot reach a decent standard of living.

It is therefore essential to carefully monitor poverty issues in order to enable policy makers to focus policies more at subnational level (Fabrizi et al., 2005) and therefore to intervene more effectively at territorial level.

Various indicators for monitoring household poverty levels, food poverty and access to food have been proposed in literature (Beacom et al., 2020b) with two broad macro-areas identified for assessing, monitoring and evaluating (in)security issues by using household survey data (Moltedo et al., 2014). On one hand, the access to diet and quality of diet-also called diet quantity and diet quality dimension by the International Food Policy Research Institute (Smith \& Subandoro, 2007)—investigates the essential requirement in terms of dietary energy and macro-nutrients requirements, the average consumption of micro-nutrients, amino acids and diversity (quality) of diets. On the other hand, the economic access to food or economic vulnerability dimension investigates the average food consumption and dietary energy unit value expressed in local monetary units, the sources of food acquisition by distinguishing shares of food purchased, own-produced and food consumed away from home, the share of food consumption over total income or consumption expenditure (Engel ratio) as well as the responsiveness of demand to income inequality (income elasticity) and the issue of food inadequacy, by means the prevalence of undernourishment and depth of food deficit.

Our study contributes to the second macro area, focusing on the economic access to food and vulnerability, by presenting and estimating statistical measures closely related and consistent with those proposed and used for the measurement of the general economic poverty, through the exploration of the data available in the HBSs (Sibrian, 2008).

\subsection{The Proposed Measures and Methods of Estimations}

\subsubsection{The Distribution of Food Expenditure and the Share of Household Expenditure on Food (SHEoF)}

The first simple measure we explore for the analysis of food poverty is represented by the expenditure on food per person $p$ in household $j$, obtained as the ratio between household consumption expenditure on food and non-alcoholic beverages and household size.

Secondly, the Share of Household Consumption Expenditure spent on Food (SHEoF or SIF), also called the Engel ratio (Moltedo et al., 2014), is introduced as an important indicator of household food security (and contrastingly of household food insecurity and economic poverty), since the poorer and more vulnerable the household, the greater the share of household income spent on food while the food ratio declines according to level of income.

The SHEoF indicator is generally calculated at household level due to the availability of official national representative HBS microdata. Without loss of generality, let $X_{j F}$ be the expenditure for Food and non-alcoholic beverages (Division 01) of household $j(j=1, \ldots, n)$, and let $X_{O j}$ be the total consumption expenditure of household $j$, then 


$$
\operatorname{SHEoF}_{j}=\frac{X_{j F}}{X_{O j}} \cdot 100
$$

The SHEoF has also been included in the Food and Agriculture Organization (FAO) set of food security indicators (INDDEX Project, 2018) as the share of food expenditure of the poor, defined as the population belonging to the first income quintile. Moreover, the SHEoF indicator is useful for understanding the impact of food price fluctuations on both the quality and quantity of household food consumption.

At regional level, the SHEoF was estimated as follows:

$$
S H E o F_{r}=\frac{\sum_{j=1}^{n \_r} S H E o F_{j r} w_{j r}}{\sum_{j=1}^{n \_r} w_{j r}},
$$

where $S H E O F_{j r}$ was defined according to Eq. (1) for household $j$ in region $r$ and $w_{j r}$ was its survey weights.

\subsubsection{At Risk-of-Food-Poverty (ARoFP)}

3.2.2.1 At Risk-of-Food-Poverty at Regional Level Bearing in mind the expenditure-based approach and the classical At-Risk-of-Poverty (ARoP) method used to define the incidence of relative poverty in the European Union, it is essential to construct specific food poverty lines. Our proposal is to define a Food (relative) Poverty Line (FPL), which is a threshold for identifying households and persons who are at risk of food poverty. Since it is difficult to significantly reduce household food expenditure, in order that households are able to meet their minimum needs other than food, it is essential to define a food expenditure threshold below which a household can be defined as in relative food poverty.

More specifically, our proposal is to set the food poverty line at $60 \%$ of the median equivalized food consumption expenditure, therefore households with a food consumption expenditure level below the food poverty lines are classified food poor.

Given that food consumption behaviour varies significantly between and within Italian regions (Marchetti \& Secondi, 2017; Secondi, 2021), we decided to compute the food poverty line at regional as suggested by Biggeri and Pratesi (2017) and Biggeri et al. (2018), in order to account for sub-national diversity (Alaimo \& Maggino, 2020) in line with the study by Campiglio and Rovati (2009).

Therefore, regional FPLs are defined as $60 \%$ of the median regional equivalised food consumption expenditure and were estimated as follows:

$$
F P L_{r}=0.6 \cdot \widehat{M e}\left(\frac{y_{j r}}{\sqrt{a_{j r}}} w_{j r}, j=1, \ldots, n_{r}\right),
$$

where $\widehat{M e}\left(u_{j}, j=1, \ldots, n\right)$ is an estimator of the median based on the weighted empirical cumulative distribution function as proposed by Woodruff (1952), $j$ is the indicator for the sampled households and $r$ for the regions, $y_{j r}$ represents the household food consumption expenditure, $a_{j r}$ is the household size-therefore $y_{j r} / \sqrt{a_{j r}}$ is the equivalized household food consumption expenditure and lastly $w_{j r}$ is the survey weight accounting for nonresponse with $n_{r}$ is the sample size in region $r$. 
According to the estimated FPL described above, the regional ARoFP rate was obtained as the proportion of those individuals with equivalized household food consumption expenditure below the FPL which was estimated as:

$$
\begin{array}{r}
A R o F P_{r}=\frac{\sum_{j=1}^{n_{r}} I\left(\frac{y_{j r}}{\sqrt{a_{j r}}}<F P L_{r}\right) w_{j r}^{*}}{\sum_{j=1}^{n_{r}} w_{j r}^{*}} \\
I\left(\frac{y_{j r}}{\sqrt{a_{j r}}}<F P L_{r}\right)= \begin{cases}1 & \text { if } \frac{y_{j r}}{\sqrt{a_{j r}}}<F P L_{r} \\
0 & \text { otherwise }\end{cases}
\end{array}
$$

where $w_{j r}^{*}$ is the survey weight of household $j$ in region $r$ so that $\sum_{j=1}^{n_{-} r} w_{j r}^{*}=N_{r}$, with $N_{r}$ the population (persons) size of region $r$.

To obtain the ARoFP rate, the equivalized food consumption expenditure is obtained using the square root scale (OECD, 2008, 2011) dividing it by the square root of the household members. This method is similar to the usual ARoP threshold used to define the incidence of poverty in the EU.

In addition to the ARoFP indicator presented above, we carried out a comparison between food poor and relatively monetary poor households, as reported in Sect. 4.5 below.

3.2.2.2 At Risk-of-Food-Poverty at Provincial Level Besides estimating specific regional FPLs and rates, we considered of some interest to investigate the presence of food poverty heterogeneity within the Italian regions, therefore we estimated the food poverty rates at provincial level. Unfortunately, the sample sizes of the 2017 HBS at provincial level are small and range from 20 to 1036 households, with a mean of 158.4 and a median of 125 households, for the 107 Italian provinces.

When the sample size of an area (or domain) is small, the estimators based on area-specific data only - i.e. direct estimators - are usually unreliable, due to their unacceptably large variance. Small area estimation (SAE) methods aim to obtain reliable estimates by using indirect or model-based estimators and proved to be suitable for obtaining robust and consistent intra-country economic measures (Marchetti \& Secondi, 2017; Pratesi et al., 2013). A detailed review of SAE methods can be found in Pfeffermann (2013), Rao and Molina (2015) and Pratesi (2016).

Here, we briefly illustrate the SAE method we have decided to use, given the available data. Let us assume that there are $m$ small areas of interest and that $\theta_{i}=1, \ldots, m$ represents the population parameter of interest in area $i$, such as a mean, a proportion or a total of the study variable $Y$. Let $\hat{\theta}_{i}=\sum_{j=1}^{n_{i}} w_{i j} y_{i j} / \sum_{j=1}^{n_{i}} w_{i j}$ be the design-unbiased direct estimator of $\theta_{i}$. where $y_{i j}$ is the study variable for the unit $j$ in area $i, n_{i}$ is the sample size in area $i, w_{i j}$ is the survey weight of unit $j$ in area $i$. Let $e_{i} \sim N\left(0, \psi_{i}\right)$ be the sampling error in area $i$, where $\psi_{i}$ is considered known, and let $\boldsymbol{X}_{i}$ be a $p$-vector of auxiliary variables for area $i$, known without error - i.e. without sampling and non-sampling errors. Letting $\hat{\theta}_{i}=\theta_{i}+e_{i}$ and assuming $\theta_{i}=\boldsymbol{X}_{i}^{T} \boldsymbol{\beta}+u_{i}$, we obtain the basic area-level model (Fay \& Herriot, 1979):

$$
\hat{\theta}_{i}=\boldsymbol{X}_{i}^{T} \boldsymbol{\beta}+u_{i}+e_{i}
$$


where $\boldsymbol{\beta}$ is a $p$-vector of regression parameters, $u_{i}$ is a random area specific effect that is assumed to be independent and normal distributed with zero mean and variance $\sigma_{u}^{2}$. Let also assume $u_{i}$ and $e_{i}$ are independent for all $i=1, \ldots, m$.

Under the above model, the Best Linear Unbiased Predictor (BLUP) is (Rao \& Molina, 2015):

$$
\tilde{\theta}_{i}^{S A E}=\gamma_{i} \hat{\theta}_{i}+\left(1-\gamma_{i}\right) \boldsymbol{X}_{i}^{T} \tilde{\beta}
$$

where $\gamma_{i}=\sigma_{u}^{2} /\left(\sigma_{u}^{2}+\psi_{i}\right)$ and $\tilde{\beta}$ is the best linear unbiased estimator of $\boldsymbol{\beta}$, which depends on the unknown parameter $\sigma_{u}^{2}$. Using the restricted maximum likelihood (other methods are possible, see Rao \& Molina, 2015) we can obtain an estimate of $\sigma_{u}^{2}$, and then an estimate of $\boldsymbol{\beta}$, which we denote by $\hat{\sigma}_{u}^{2}$ and $\hat{\beta}$ respectively. Then the empirical best linear unbiased predictor (EBLUP) is (Rao \& Molina, 2015):

$$
\hat{\theta}_{i}^{S A E}=\hat{\gamma}_{i} \hat{\theta}_{i}+\left(1-\hat{\gamma}_{i}\right) \boldsymbol{X}_{i}^{T} \hat{\beta}
$$

The mean squared error (MSE) of the EBLUP is not straightforward to estimate and different method exist in literature (Rao \& Molina, 2015).

Given that the direct estimator used in the model is a ratio, like the SHEoF or the ARoFP rate, we decided to use a popular arcsin transformation (Casas-Cordero et al., 2016, Schmid et al., 2017 and Jiang et al., 2001), with a back-transformation for bias correction proposed by Sugawasa and Kubokawa (2017) and Hadam et al. (2020). The R package "emdi" (Kreutzmann et al., 2019) was used to compute the estimates.

\subsubsection{Food Insecure Households (FIH)}

There are several ways of interpreting the SHEoF indicator with the aim of linking food expenditure to poverty and food (in)security, however the usual practice is to refer to existing international studies and standards (Armstrong et al., 2019). One of these standards is the Integrated Food Security Phase Classification (IPC) which is an innovative multipartner initiative for improving food security, nutrition analysis and decision-making procedures addressing poverty issues (IPC, 2021). Originally introduced by FAO's Food Security and Nutrition Analysis Unit, the IPC has provided policy makers with a rigorous, evidence and consensus-based analysis of food insecurity, by proposing a 4-group classification:

i. No food insecurity if $\mathrm{SHEoF}<40 \%$;

ii. mild food insecurity if $40 \% \leq \mathrm{SHEoF}<50 \%$;

iii. moderate food insecurity if $50 \% \leq \mathrm{SHEoF}<70 \%$

iv. severe food insecurity if $\mathrm{SHEoF} \geq 70 \%$.

These thresholds are used by IPC together with other measures, which are not available from HBS or are not considered in developed countries.

The proportion of persons in each level $l$ of food insecurity were estimated at regional level as follows:

$$
F I_{l, r}=\frac{\sum_{j=1}^{n_{r}} I\left(S H E o F_{j r} \in S_{l}\right) w_{j r}^{*}}{\sum_{j=1}^{n_{r}} w_{j r}^{*}} ; l=1,2,3,4 ; r=1, \ldots, 20,
$$




$$
S_{1}=(0,40] ; \quad S_{2}=(40,50] ; \quad S_{3}=(50,70] ; \quad S_{4}=[70,100]
$$

where $w_{j r}^{*}$ is the same quantity as in (2), $S H E o F_{j r}$ is the same as in (1) referring to household $j$ in region $r, S_{l}$ is the set defining the food insecurity level $l$ and $I\left(S H E o F_{j r} \in S_{l}\right)$ is the indicator function, being equal one if $S H E o F_{j r}$ is in the set $S_{l}$ and zero otherwise.

The thresholds for the four food insecurity levels were originally introduced for developing countries or where proper nutrition represents serious issues for the population while access to food is seldom a problem in developed countries. However, we decided to leave the thresholds as they were originally established, but we consider households with mild, moderate or severe food insecurity (corresponding to the groups 2, 3 and 4 according to the classification described above) to be in danger and they should be collectively labelled as Food Insecure Households (FIH), with.

$$
F I H_{r}=F I_{2, r}+F I_{3, r}+F I_{4, r}=1-F I_{1, r}
$$

Indeed, in order to live a good and "decorous" life, one requires a comfortable and adequate home and the possibility to spend for health and a varied social life (one requires a comfortable home, good health and social life). If a large part of the household consumption expenditure is spent on food, little remains for housing, health and social life.

\subsubsection{Measures for Assessing Differences in Food Expenditure Classes}

With the aim of investigating differences in food type expenditure distributions, we focused on the empirical distributions of the 11 food classes introduced in Sect. 2 in order to evaluate whether and to what extent the observed distributions deviate from a situation of equal distribution thus disentangling the existence of inequalities between food poor (food-insecure) and non-food poor (food secure) families.

As described in the next section, we firstly referred to the class of Percentile Ratio indexes and specifically to the $\mathrm{P}_{90} / \mathrm{P}_{10}$ ratio-defined by $\operatorname{OECD}(2008,2019)$ as the ratio between the minimum level of food expenditure of the "highest" $10 \%$ of the households and the level of maximum expenditure of the first $10 \%$ of the "poorest-and to the Gini concentration coefficient, which can be interpreted as a normative index thus reflecting the principle of relative deprivation (Mookodi, 2021).

However, in order to decompose the inequalities between poor and non-poor according to the computed Regional Food Poverty Lines (RFLP), the relative measures of inequality included within the GE family (Rohde, 2008) were used to split them into two additive parts within and between groups.

For the variable $X$ let us assume that $x \in X$ is a specific value of the variable under study while $F$ represents the cumulative distribution of the expenditure with $F\left(x_{0}\right)$ capturing the proportion of the population with food expenditure less than or equal to $x_{0} \in \mathbb{R}$. In our study, the variable $\mathrm{X}$ is represented by the expenditure for each of the 11 food classes. According to this approach, the GE family of measures (Cowell \& Kuga, 1981a, 1981b) which incorporates the Kullback's (1959) original information-theoretic ideas - can be described by the following general equation (Cowell, 2011):

$$
I_{G E}^{\alpha}(F)=\frac{1}{\alpha^{2}-\alpha} \int\left[\left[\frac{x}{\mu(F)}\right]^{\alpha}-1\right] d F_{(x)}
$$

where $\alpha \in \mathbb{R}$ is a parameter capturing the sensitivity of a specific GE index to particular parts of the distribution: for large and positive values of $\alpha$ the index obtained is sensitive to 
changes in the distribution affecting the upper tail. Conversely, the obtained index is more sensitive to changes in the distribution that affect the lower tail for negative values of $\alpha$.

Specifically, when $\alpha=1$ the well-known inequality measure introduced by Theil (Theil, 1967) that is usually indicated a GE (1). We therefore estimated the Theil index which satisfies the additive decomposability within and between groups.

The GE(1) index was estimated for each of the 11 food classes constituting the Food and non-alcoholic beverages division (Division 01) together with the bootstrapped standard errors obtained by running 1,000 replications as well as the related decomposition was carried out for the $\mathrm{J}=2$ sub-categories, represented in turn by food poor and non-food poor and food-secure and food insecure households.

The estimation and decomposition of the Theil index address a limitation of our study which cannot consider a pure qualitative component of food expenditure since the HBS did not include this information. However, by examining the diversity of inequalities among expenditure classes and between poor (food insecure) and non-poor (food secure), we performed an extended analysis of poverty, food poverty and insecurity issues- which determine socioeconomic spill over in terms of productivity and health-care expenditure (Carrillo-Álvarez et al., 2021)—oriented to a more detailed exploration of the economic ability of accessing to a nutritious and healthy diet (Bai et al., 2021; Vilar-Compte et al., 2021).

\section{Results}

In this section estimates regarding food expenditure, the SHEoF, the regional FPLs, the ARoFP and FIH rates are reported and compared with each other and with the relative economic poverty measure. Estimates were carried out for the 20 Italian regions. The ARoFP rates were estimated also for the 107 Italian provinces, by using SAE methods, to investigate in part the presence of food poverty heterogeneity within the Italian regions. We then analysed food expenditure inequalities and their decomposition across food classes between households in food poverty, food insecurity or not.

\subsection{Distribution of Food Expenditure and SHEoF at National and Regional Levels}

Figure 1 shows the empirical distribution of the monthly per capita expenditure on food, with an estimated mean per capita equal to 225.75 Euros (standard error 1.51 euros) and a coefficient of variation equal to $0.67 \%$ as reported in Table 1 , which also details the estimated values for the Italian regions.

The estimated monthly regional expenditure on food ranges from approximately 200 Euros observed for Sicily and Abruzzo up to 280 Euros for Valle d'Aosta region, whose mean differs significantly to those of the other regions. Valle d'Aosta is also the region for which we observed the highest level of variability (CV equal to $5.06 \%$ ) followed by Sardinia $(\mathrm{CV}=4.31 \%)$ and Molise $(3.92 \%)$.

On comparing the regional distributions of the per capita consumption expenditure on food, reported in Fig. 2, similarities in the shape can be observed except for the distributions of Valle d'Aosta and Liguria.

Regarding the SHEoF, the related distributions were estimated both at national and regional level as shown in Figs. 3 and 4. 


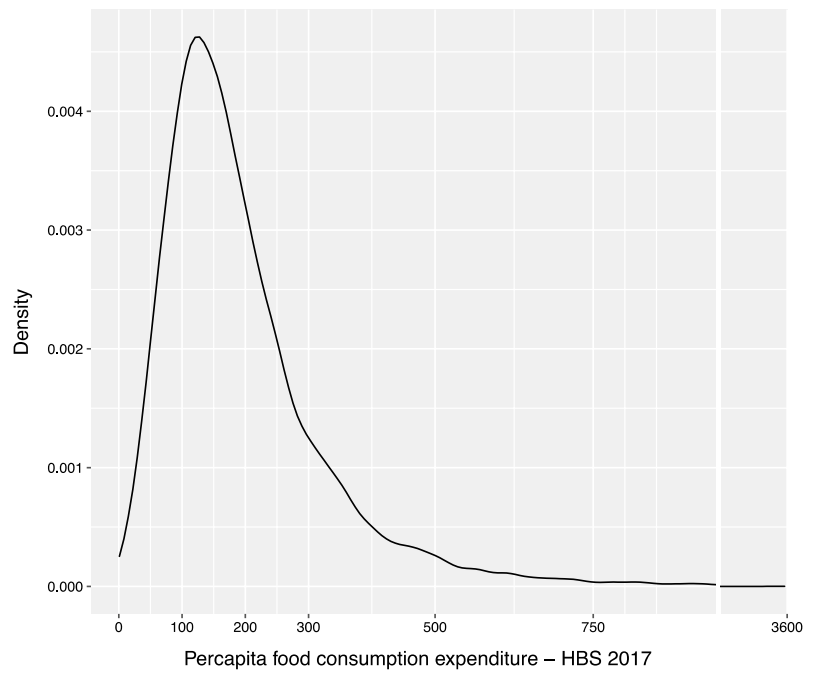

Fig. 1 Distribution of monthly expenditure on food per capita (in Euros)

Table 1 Regional estimates of monthly expenditure on food per capita (in Euros)

\begin{tabular}{|c|c|c|}
\hline Region & $\begin{array}{l}\text { Food per capita expenditure } \\
\text { (in Euros) }\end{array}$ & $\mathrm{CV}(\%)$ \\
\hline Piemonte & 254.48 & $2.33 \%$ \\
\hline Valle d'Aosta & 280.07 & $5.06 \%$ \\
\hline Lombardia & 239.99 & $1.81 \%$ \\
\hline Trentino-Alto Adige & 232.73 & $3.04 \%$ \\
\hline Veneto & 207.51 & $2.27 \%$ \\
\hline Friuli-Venezia Giulia & 228.36 & $3.05 \%$ \\
\hline Liguria & 248.07 & $3.10 \%$ \\
\hline Emilia-Romagna & 230.71 & $2.47 \%$ \\
\hline Toscana & 231.80 & $2.58 \%$ \\
\hline Umbria & 213.27 & $3.51 \%$ \\
\hline Marche & 219.97 & $3.42 \%$ \\
\hline Lazio & 233.41 & $1.80 \%$ \\
\hline Abruzzo & 199.70 & $3.48 \%$ \\
\hline Molise & 205.61 & $3.92 \%$ \\
\hline Campania & 211.89 & $2.54 \%$ \\
\hline Puglia & 203.51 & $2.77 \%$ \\
\hline Basilicata & 233.00 & $3.30 \%$ \\
\hline Calabria & 218.06 & $3.61 \%$ \\
\hline Sicilia & 199.83 & $2.87 \%$ \\
\hline Sardegna & 224.98 & $4.31 \%$ \\
\hline ITALY & 225.75 & $0.67 \%$ \\
\hline
\end{tabular}




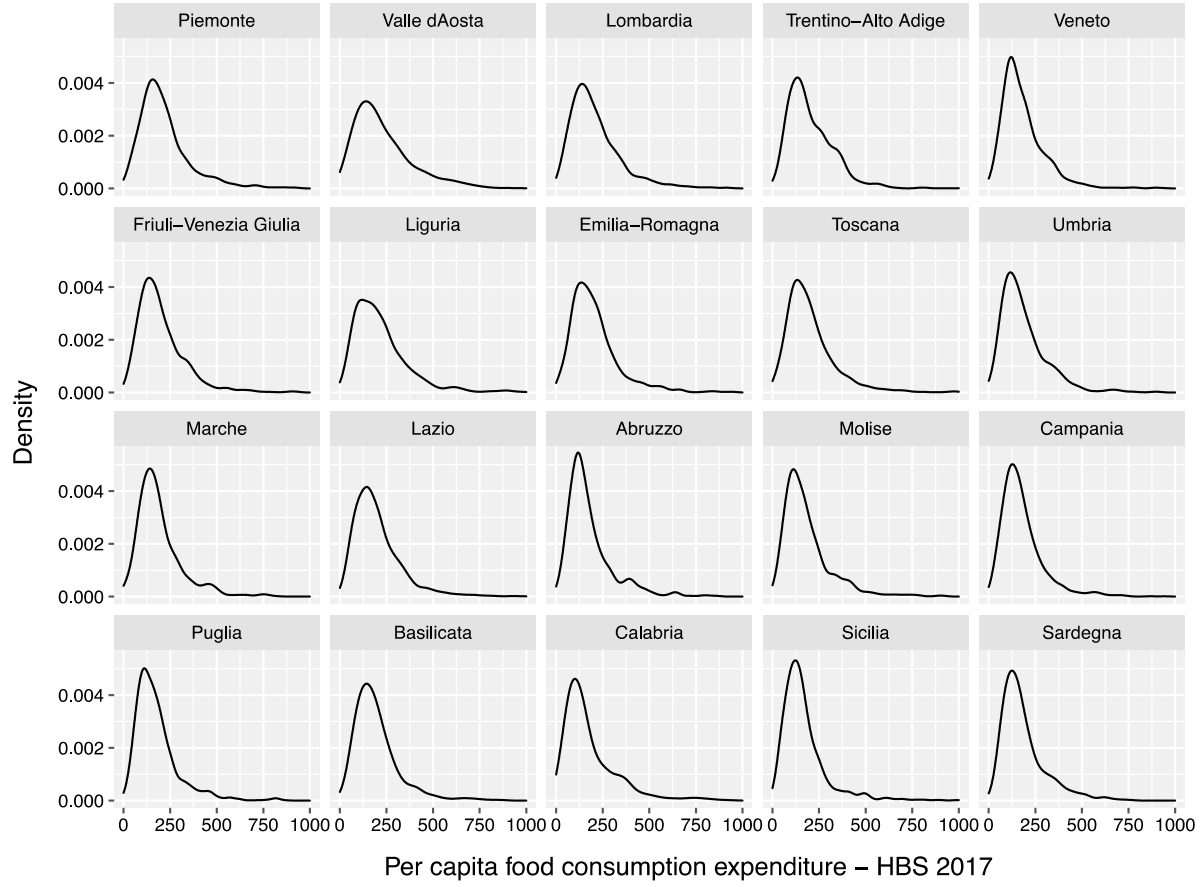

Fig. 2 Regional distributions of the per capita food consumption expenditure (in Euros)

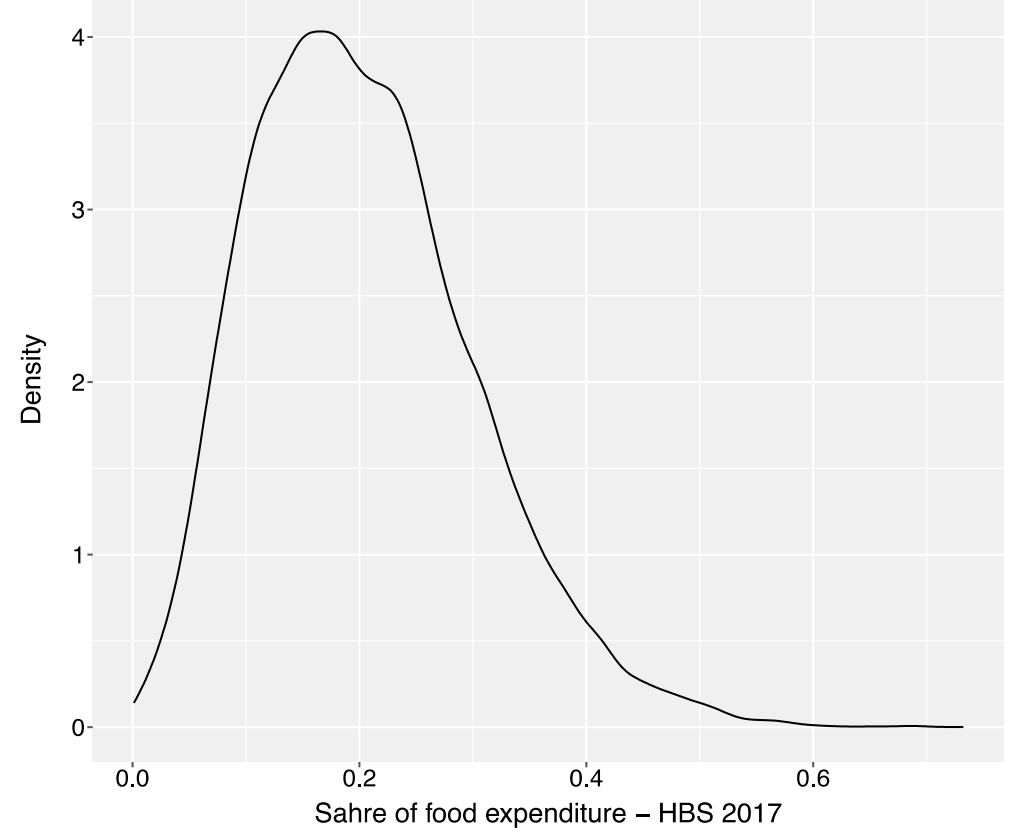

Fig. 3 Estimation of the SHEoF distribution in Italy 


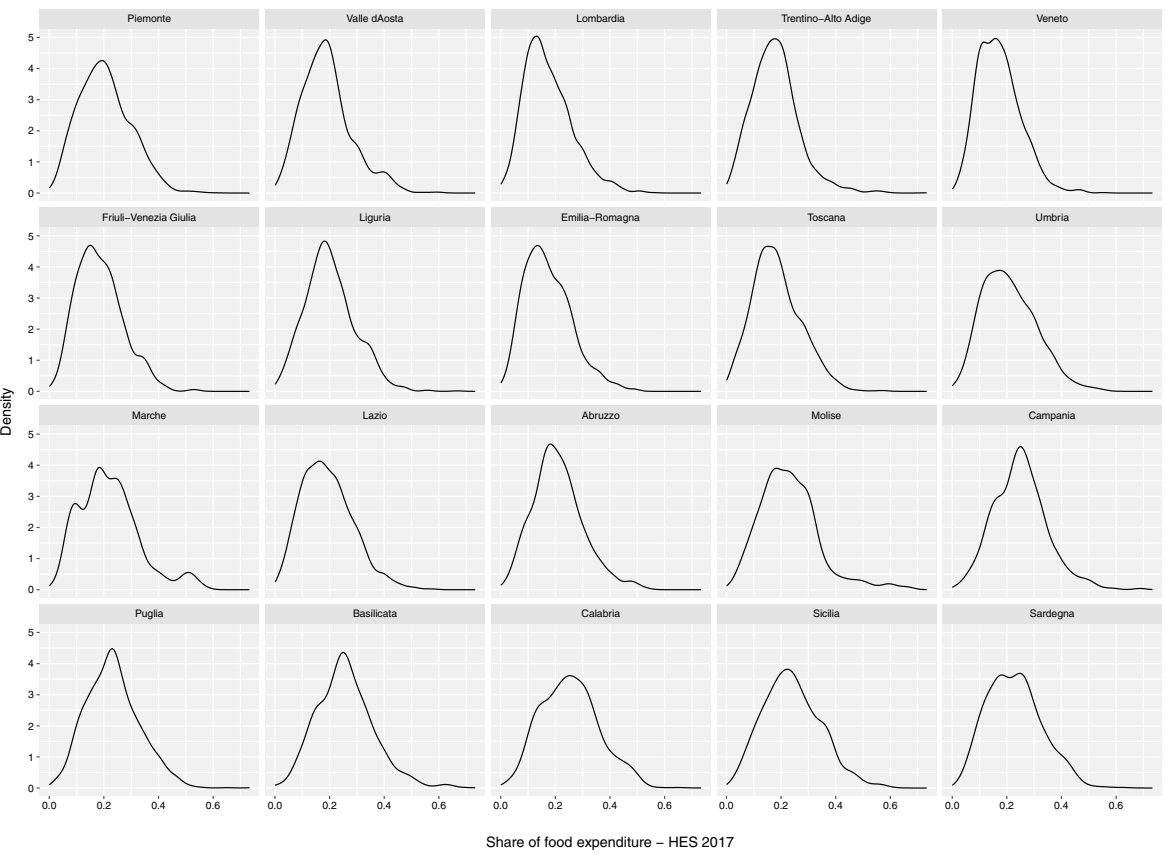

Fig. 4 Distribution of the SHEoF by regions

At national level the estimated SHEoF amounted to 0.196 (standard error 0.001), while it ranged between 0.166 (Emilia-Romagna) and 0.258 (Basilicata) which was a very high regional value statistically different from the others.

On comparing the regional SHEoF distributions in Fig. 4, differences can be noted in the shape, even though left skewness and long right tails are commonly observed. The SHEoF is used to define food insecurity levels, which will be discussed later in this section. Therefore, its distribution at regional level illustrates the risks of food insecurity, and future in-depth studies could provide useful insights into the distribution of households at maximum risk of food insecurity.

\subsection{Food Poverty Lines (FPLs) and At-Risk-of-Food-Poverty (ARoFP) Rates}

The regional FPLs are shown in Fig. 5 and ranges from 142 Euros in Abruzzo to 183 Euros in Valle d'Aosta, while the national FPL is 162 Euros. As expected, and by considering the existing differences in relative prices across regions (Marchetti \& Secondi, 2017), most of the Southern regions show a FPL below the national FPL values while most of the Northern regions show the opposite. However, Campania and Basilicata (two southern regions) have a FPL higher than the national value, with Basilicata having the second highest FPL.

Although the regional FPLs represent estimates, and therefore are characterized by a certain degree of variability, they were treated as known constant for two main reasons: (1) To facilitate the analysis and the estimation of food poverty rates and standard errors, and (2) because of small estimated standard errors for most of the regional FPLs. 


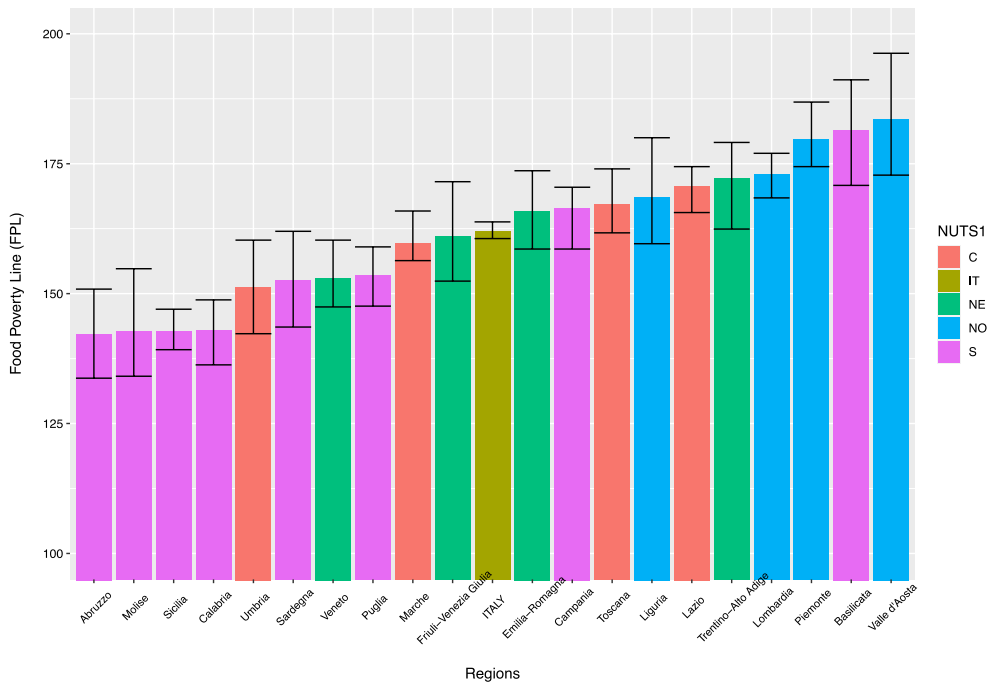

Fig. 5 Regional FPLs by NUTS1 (C: center, IT: Italy, NE: northeast, NO: northwest, S: south)

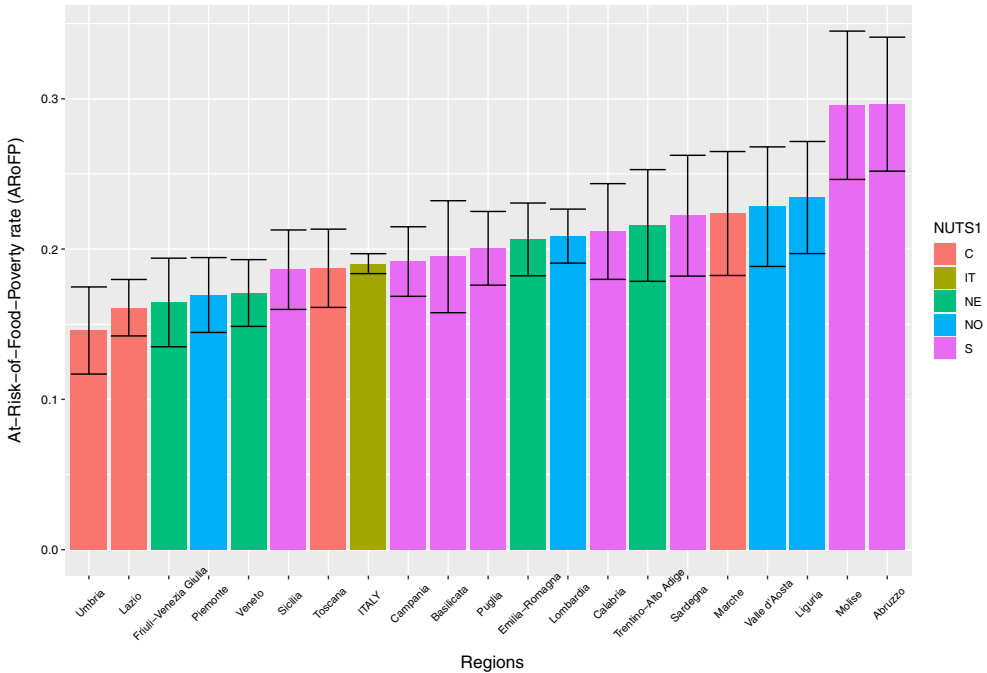

Fig. 6 Regional ARoFP rates with 90\% confidence bars by NUTS1 (C: center, IT: Italy, NE: northeast, NO: northwest, S: south)

The results of the regional ARoFPs rates are shown in Fig. 6. The lowest estimated ARoFP rate equal to 0.146 was observed in Umbria (central Italy), while the highest rate equal to 0.296 was found in Abruzzo, even if it has the lowest FPL. The Italian ARoFP rate is equal to 0.190 (standard error, s.e., 0.004), that means 11,459,795 persons ARoFP (s.e. 257,012). Considering households instead of persons, we estimated a ARoFP rate equal to 0.206 (s.e. 0.004), corresponding to 5,320,716 households (s.e. 96,403). We estimated the ARoFP also using a FPL set to 0.5 and 0.4 times the median household consumption 
expenditure for food, obtaining for the persons a ARoFP rate equal to 0.127 (s.e. 0.003 ) and 0.078 (s.e. 0.003 ) respectively, corresponding to 7,618,030 (s.e. 212,881) persons and 4,712,194 (s.e. 170,576) persons respectively. Considering households, we obtained a rate equal to 0.142 (s.e. 0.003 ) and 0.091 (s.e. 0.003 ), corresponding to $3,662,388$ (s.e. 82,407 ) households and 2,342,200 (s.e. 67,469) households respectively.

In order to compare food poverty among the Italian regions, it is essential to consider the standard errors of the estimates, in order to avoid incorrect conclusions. Figure 7 shows 5\% significance differences between pairwise regional ARoFP rates. Tests were carried out by comparing pairwise $95 \%$ confidence bounds obtained using a Wald-type interval on the log-odds scale, which was then transformed to the probability scale. Most of the regions did not reveal significantly different ARoFP rates, however, we some significant difference (red squares) can be seen. More specifically, Abruzzo and Molise have significantly different ARoFP rates to many other regions (13 and 12 respectively). Moreover, Umbria, Lazio, Abruzzo, and Molise show significant differences in their ARoFP rates compared to the national value.

\subsection{At-Risk-of-Food-Poverty Rates at Provincial Level}

The estimation of the at ARoFP rate has been computed as described in the Sect. 3.2.2. As auxiliary variable we used the ratio between the number of persons declaring income and the population, following the work by Fabrizi et al (2016). These data refer to the year 2017 and were obtained from the Italian Tax Agency register, which releases data aggregated at municipality level (LAU 2) every year. Other variables obtained from the Tax Agency register and other population registers such as demographic data, were included in the arealevel model, without obtaining satisfactory results. Model diagnostics and information on direct estimates are not included in this paper but are available upon request to the authors.

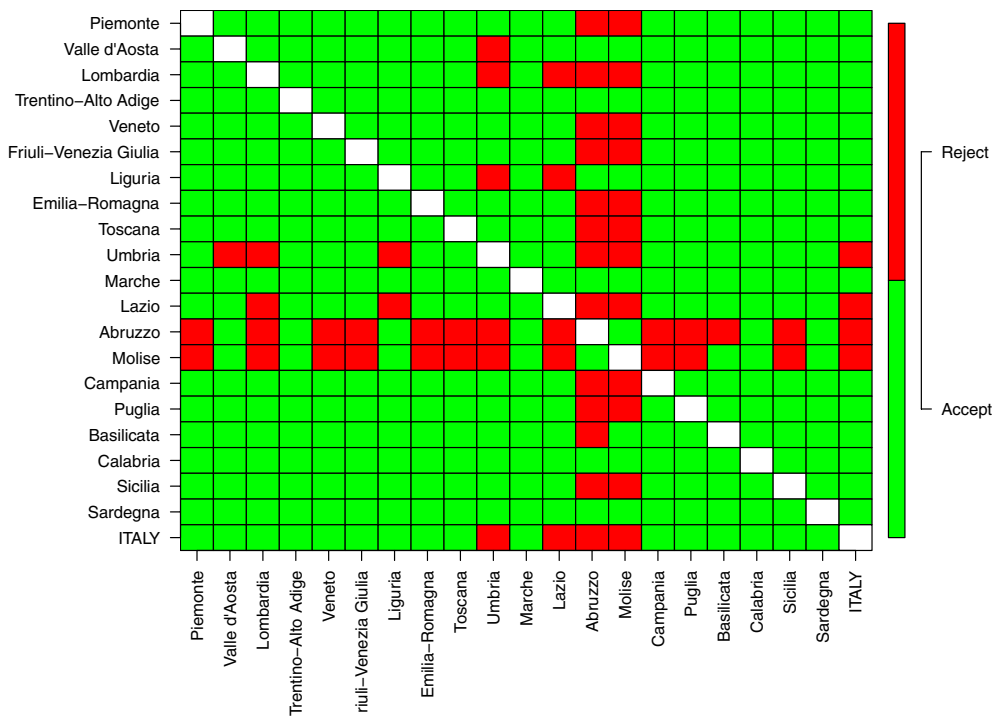

Fig. 7 Pairwise test of hypothesis on ARoFP rates differences between regions, 5\% significance (null hypothesis is ARoFP are equal) 
SAE estimates show a gain in efficiency compared to direct estimates. Of 107 sampled provinces, 54 estimated ARoFP rates proved to be reliable (CV lesser than 16\%), 51 were reliable with warning to users (CV between 16 and 30\%) while only 2 were unreliable (Belluno and Rieti), with a CV of $40 \%$ and $45 \%$, respectively. Therefore, comments are made with caution.

The heterogeneity of the ARoFP rates is evident with one of the most marked differences for the two provinces - Trento and Bolzano-of Trentino-Alto Adige (Sud-Tirol) region as Trento of has one of the lowest ARoFP rates equal to $14.4 \%$ Bolzano has one of the highest ARoFP rate which is estimated at 27.5\%, while the ARoFP rate of the entire Trentino-Alto Adige region amounts to $21.6 \%$.

As shown in Fig. 8, the lowest ARoFP rate of 9.8\% was estimated for Alessandria (AL) while the highest of $45.7 \%$ was estimated for L'Aquila (AQ) which also differ significantly $(10 \%)$ to all the other provinces.

\subsection{Food Insecurity}

As expected, most households are not food insecure, as shown in Fig. 9, even if it cannot be considered a marginal and negligible phenomenon, with the estimated regional FIH rates range from $0.9 \%$ in Veneto to $9.7 \%$ in Calabria while the national FIH rate is equal to $3.6 \%$, as more than two million persons spend more than $40 \%$ of their total expenditure on food and beverages (non-alcoholic).

As expected, many southern regions show higher FIH rates than the northern and central regions, except for Marche, which is a central region with the third highest FIH rate (equal 0.069).

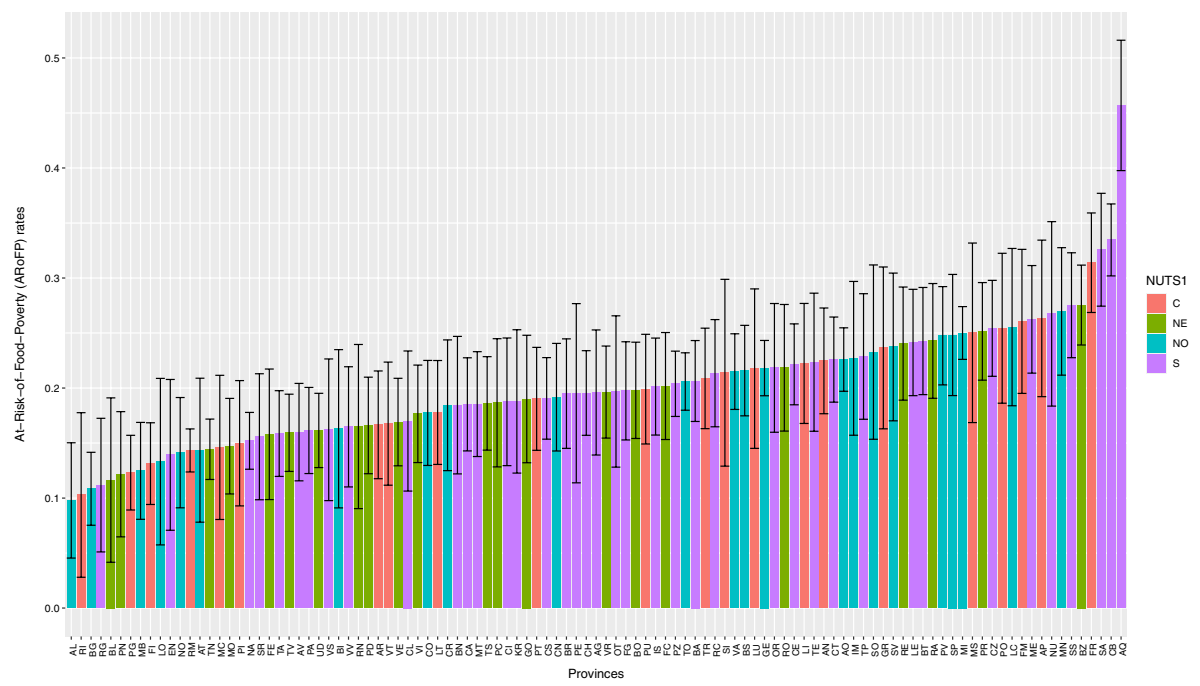

Fig. 8 Provincial ARoFP rates with 90\% confidence bars (SAE estimates) by NUTS1 (C: center, IT: Italy, NE: northeast, NO: northwest, S: south) 
Fig. 9 Fraction of food insecurity households, by regions

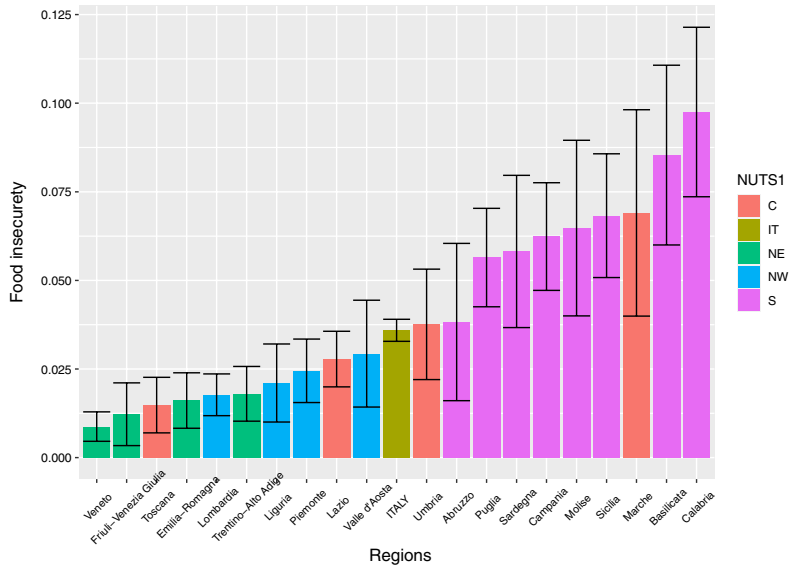

\subsection{Comparing Food Insecurity, Food Poverty and Relative Monetary Poverty}

Four measures related to food consumption were introduced in our study: food per capita consumption expenditure, share of food consumption (SHEoF), at-risk-of-food-poverty (ARoFP) rate - which is based on regional specific food poverty lines - and percentage of food insecure households (FIH). In this section these regional measures are compared and cross-tabulations between FIH and ARoFP are presented. Moreover, the cross-tabulations between monetary poverty and food poverty are analysed.

Let us start by comparing the ARoFP and FIH rates shown in Fig. 10. Four regions, namely Calabria, Sardegna, Molise and Marche, have ARoFP and FIH rates above the mean (that is zero in the standardized scale). In the previous section these four regions were highlighted as having very high FIH values and are therefore the regions with the worst scenario in this prospect.

Six regions - two north-east regions (Friuli-Venezia-Giulia and Veneto), one northwest region (Piemonte) and three central regions (Umbria, Lazio and Toscana)—all show

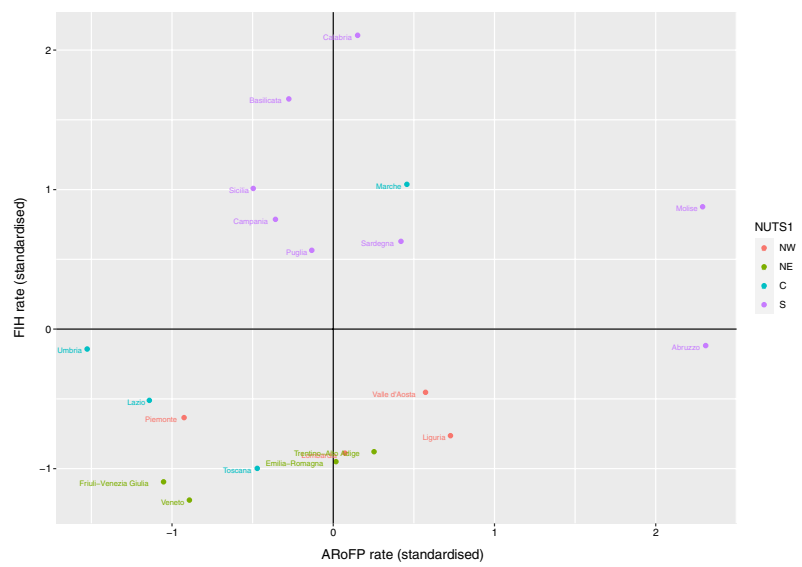

Fig. 10 Scatter plot of ARoFP and FIH rates in standardized scale 
Table 2 Estimated crosstabulation between food poor and food insecure individuals

\begin{tabular}{llll}
\hline & & \multicolumn{2}{l}{ Food poor } \\
\cline { 3 - 4 } & & No & Yes \\
\hline Food insecure & No & 0.777 & 0.187 \\
& Yes & 0.028 & 0.008 \\
\hline
\end{tabular}

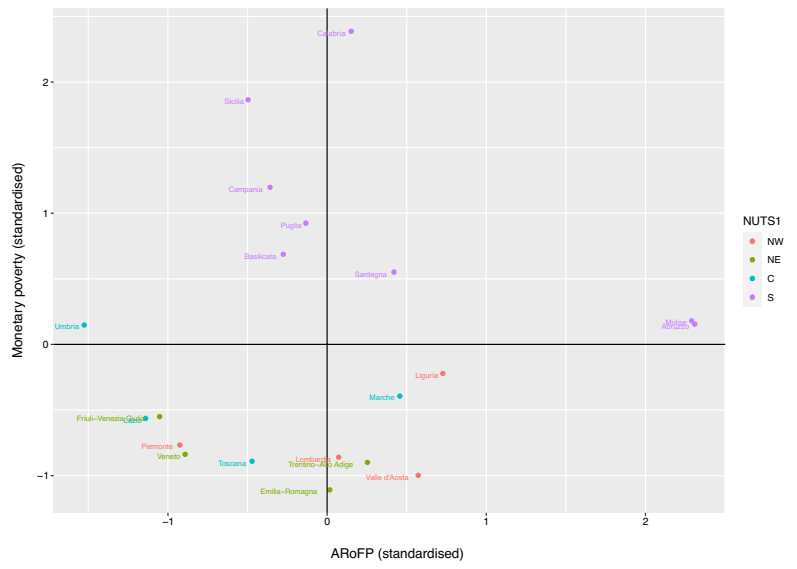

Fig. 11 Scatter plot of ARoFP rate and monetary relative poverty rate in standardized scale

ARoFP and FIH rates below the mean, therefore they have the best scenario. Moreover, four Southern regions (Basilicata, Sicily, Campania and Puglia), all have FIH rates above the mean and ARoFP below the mean. Therefore, these regions are classified as being at low risk for nutrition and high risk for a "decorous lifestyle" (few resources for expenses other than food). Lastly, six regions-Lombardia, Valle d'Aosta and Liguria located in the North-West, Emilia Romagna and Trentino Alto Adige in the North-East and Abruzzo in the south have FIH rates below the mean and ARoFP rates above the mean, with Abruzzo showing a very high ARoFP level. These regions are deemed to be at high risk for nutrition (people have a lower food expenditure than expected compared to other people in the same region) and low risk for a "decorous" and good lifestyle.

The cross-tabulation between FIH and ARoFP rates is reported in Table 2. Approximately $78 \%$ of people were deemed to be neither food poor nor food insecure, while $0.8 \%$ people (approximately 470,000 individuals) deal with serious food-related difficulties. About 19\% have a food consumption expenditure lower than others (below the FPL), however this lower value does not reach a relevant share over the total consumption expenditure (food expenditure less than $40 \%$ of total expenditure) thus setting aside resources for other expenses. Finally, approximately $3 \%$ of persons have food consumption expenditures similar to the other inhabitants in the region, but the share of this expenditure over the total consumption expenditure is important compared to the total consumption expenditure (food expenditure is higher than $40 \%$ of total expenditure). It is more probable to be in ARoFP than FIH which was expected since ARoFP is a relative region-specific measure with a low threshold ( $60 \%$ of the median food consumption expenditure), while FIH has a very high household-specific threshold, $40 \%$ of total consumption expenditure spent on food. 
Table 3 Estimated crosstabulation between food poor and relative monetary poor individuals

\begin{tabular}{llll}
\hline & & \multicolumn{2}{l}{ Relative monetary poor } \\
\cline { 3 - 4 } & & No & Yes \\
\hline Food insecure & No & 0.823 & 0.141 \\
& Yes & 0.022 & 0.014 \\
\hline
\end{tabular}

\begin{tabular}{llll}
\hline & & \multicolumn{2}{l}{ Food poor } \\
\cline { 3 - 4 } & & No & Yes \\
\hline Relative monetary poor & No & 0.682 & 0.123 \\
& Yes & 0.162 & 0.033 \\
\hline
\end{tabular}

Table 4 Estimated crosstabulation between food insecurity and relative monetary poor individuals
Food poverty and monetary poverty are two different measures, even if together they reveal the state of wellbeing of a region. Although monetary poverty is measured using two main indicators, relative poverty and absolute poverty, as our proposed measure of food poverty - the ARoFP rate-is a relative measure we decided to compare it to the relative monetary poverty (RMP) rate, as shown in Fig. 11.

Let us note that all the southern regions and Umbria (central region) show RMP rates above the mean (that is zero in the standardized scale) thus confirming the well-known north-south economic divide in Italy. This result is mainly due to the use of a national poverty line which penalizes the southern households which proved to have higher poverty rates than those obtained using regional poverty lines, as described by Bertarelli et al. (2019) and Biggeri et al (2018).

The ARoFP rate is based on regional food poverty lines, which implicitly consider and correct for the north-south divide effect. However, the regions with RMP and ARoFP rates above the mean are in the south of Italy, Calabria, Sardegna, Abruzzo and Molise, while those with RMP and ARoFP rates below the mean are Friuli-Venezia-Giulia, Veneto (north-east), Piemonte (north-west), Lazio and Toscana (center). The regions with RMP rates above the mean and ARoFP rates below the mean are Sicily, Campania, Puglia, Basilicata (south) and Umbria (center). In these regions monetary poverty is higher than food poverty.

Liguria, Lombardia, Valle d'Aosta (north-west), Trentino-Alto Adige, Emilia-Romagna (north-east) and Marche (center) show ARoFP rates above the mean and RMP rates below the mean thus food poverty is higher than monetary poverty indicating that focusing only on monetary poverty can be misleading when related to household consumption especially in central and northern Italy.

The cross tabulation between ARoFP and RMP is reported in Table 3. Approximately $68 \%$ of individuals are neither food nor monetary poor while $3.3 \%$ (approximately two million people) have low consumption expenditure levels compared to the rest of the population and the same applies to their food expenditure levels. Approximately $12 \%$ of individuals are estimated to be only food poorwhile approximately $16 \%$ of individuals proved to be monetary poor, but not food poor thus, they are not at risk of food related issues.

Lastly, monetary poverty was compared with food insecurity by estimating the proportion of individuals characterized by FIH (counting persons) and RMP, the results of which are shown in Table 4. Food insecurity is fortunately uncommon, indeed spending a little 
more than half of one's total consumption expenditure only on food highlights one's difficulties of affording expenses for house, health and basic services required for what is known as a "good and decorous lifestyle". However, as we can see from Table 4 approximately $2.2 \%$, about 1.3 million individuals, are deemed to be food insecure but not monetary poor (the estimate is significantly different from zero). These people spent over $40 \%$ of their total consumption expenditure on food and their total consumption expenditure is consistent with non-monetary-poor persons which is an unexpected result probably because of the Carbonaro equivalence scale used for computing RMP which penalizes large households and/or the behaviour of people who are likely to spend large proportion of total expenditure on food expenditure. Monetary poor persons who are not food insecure are estimated to be approximately $14 \%$ whose food expenditure is more or less "under control" (less than $40 \%$ of total consumption expenditure), but their total consumption expenditure is considered too low compared to non-monetary poor people. Lastly, approximately $1.4 \%$ of individuals (nearly two million people) are both food insecure and monetary poor and therefore extremely vulnerable while $82 \%$ are neither food insecure nor monetary poor.

\subsection{Differences in the Distribution of Food Expenditure Classes}

According to the approach presented in Sect. 3.2.4 and by using the regional FPLs obtained in Sect. 4.2, we further explored the empirical distributions of the equivalent expenditure on food for each of the 11 classes, by estimating specific ratios and indexes aimed at revealing and disentangling the inequalities between poor and non-poor households as well as between food secure and insecure households.

Table 5 shows the estimated measures together with the related bootstrapped measures of uncertainty, with the first two columns showing the ratios between $\mathrm{P}_{90}$ and $\mathrm{P}_{10}$ (the 'decile dispersion ratio') and the related bootstrapped standard errors, while the last two columns show the estimation of the Gini coefficient and the related standard errors.

We further extended the analysis of inequalities by computing the Theil index - the GE(1) measure-measures for each food expenditure class in order to distinguish

Table 5 Percentile ratios and concentration: estimates for food categories

\begin{tabular}{lrlll}
\hline Food classes & P90/P10 & SE & Gini coefficient & SE \\
\hline Bread and cereals & 5.838 & 0.112 & 0.351 & 0.002 \\
Fish and seafood & 12.364 & 0.252 & 0.479 & 0.003 \\
Meat & 7.440 & 0.153 & 0.388 & 0.002 \\
Milk, cheese, eggs & 5.944 & 0.082 & 0.355 & 0.002 \\
Oils and fats & 12.000 & 0.241 & 0.527 & 0.006 \\
Fruit & 8.934 & 0.232 & 0.418 & 0.003 \\
Vegetables & 7.926 & 0.180 & 0.408 & 0.002 \\
Sugar, jam, honey, & 12.950 & 0.165 & 0.480 & 0.004 \\
$\quad$ chocolate and con- & & & & 0.005 \\
$\quad$ fectionery & & & & 0.003 \\
$\begin{array}{l}\text { Food products n.e.c } \\
\text { Coffee, tea and cocoa }\end{array}$ & 18.000 & 0.331 & 0.569 & 0.002 \\
$\begin{array}{l}\text { Mineral water, soft } \\
\quad \text { drink, fruit and }\end{array}$ & 16.531 & 0.578 & 0.522 & \\
$\quad$ vegetable juices & & & & \\
\hline
\end{tabular}

Bootstrapped SE based on 1000 replications 
between food poor and non-food poor as previously defined. The same analysis was carried out between food secure and insecure households. In all cases inequalities were decomposed between and within groups.

The analysis of the percentile ratios and the Gini concentration coefficient shows high global levels of concentration for consumption expenditure on fish which even if a common element of the Mediterranean diet has generally a higher price than other substitute food. High values of Gini coefficient were also observed for oils and fats and beverages (water, soft drinks and fruit and vegetable juices). Values over 0.4 of the Gini coefficient were observed for fruit and vegetables, which should always be included in one's daily diet in order to meet food safety and healthy nutrition expectancies. Lower concentration levels suggest a more equally distributed consumption of pasta, meat and dairy products, cheese and eggs for all households.

Further insights were obtained by estimating the Theil inequality measure, reported in Table 6.

The most interesting considerations that emerge from these indexes can be formulated thanks to their additive decomposition properties which enable us to distinguish between the inequality component of the subgroups and the differences observed between subgroups (Sinha \& Chaudhury, 2021).

Firstly, the breakdown of inequality between and within groups confirms and is in line with findings obtained by other similar studies focused on the disaggregation of

Table 6 Disentangling the GE(1) inequalities between FP and non FP

\begin{tabular}{|c|c|c|c|c|c|c|c|}
\hline Food classes & GE(1) & SE & GE(1) FP & GE(1) non FP & $\begin{array}{l}\text { Within } \\
\text { group } \\
\text { inequality }\end{array}$ & $\begin{array}{l}\text { Between } \\
\text { group } \\
\text { inequality }\end{array}$ & $\begin{array}{l}\% \text { of between } \\
\text { group inequality }\end{array}$ \\
\hline $\begin{array}{l}\text { Bread and cere- } \\
\text { als }\end{array}$ & 0.206 & 0.003 & 0.222 & 0.202 & 0.20250 & 0.00012 & 0.053 \\
\hline Fish and seafood & 0.395 & 0.006 & 0.387 & 0.397 & 0.39531 & 0.00007 & 0.018 \\
\hline Meat & 0.253 & 0.003 & 0.277 & 0.248 & 0.25317 & 0.00026 & 0.103 \\
\hline $\begin{array}{l}\text { Milk, cheese, } \\
\text { eggs }\end{array}$ & 0.211 & 0.003 & 0.227 & 0.206 & 0.21030 & 0.00022 & 0.105 \\
\hline Oils and fats & 0.588 & 0.026 & 0.601 & 0.584 & 0.58773 & 0.00005 & 0.009 \\
\hline Fruit & 0.296 & 0.004 & 0.316 & 0.290 & 0.29537 & 0.00024 & 0.078 \\
\hline Vegetables & 0.283 & 0.004 & 0.304 & 0.278 & 0.28289 & 0.00046 & 0.162 \\
\hline $\begin{array}{l}\text { Sugar, jam, } \\
\text { honey, } \\
\text { chocolate and } \\
\text { confectionery }\end{array}$ & 0.396 & 0.005 & 0.424 & 0.389 & 0.39538 & 0.00014 & 0.035 \\
\hline $\begin{array}{l}\text { Food products } \\
\text { n.e.c }\end{array}$ & 0.620 & 0.017 & 0.581 & 0.629 & 0.62010 & 0.00017 & 0.026 \\
\hline $\begin{array}{l}\text { Coffee, tea and } \\
\text { cocoa }\end{array}$ & 0.374 & 0.007 & 0.388 & 0.370 & 0.37372 & 0.00005 & 0.013 \\
\hline $\begin{array}{l}\text { Mineral water, } \\
\text { soft drink, fruit } \\
\text { and vegetable } \\
\text { juices }\end{array}$ & 0.474 & 0.006 & 0.481 & 0.472 & 0.47345 & 0.00073 & 0.154 \\
\hline
\end{tabular}

Bootstrapped SE based on 1000 replications 
Table 7 Disentangling the GE(1) inequalities between FIH and non-FIH

\begin{tabular}{|c|c|c|c|c|c|}
\hline Food classes & GE(1) FIH & GE(1) non-FIH & $\begin{array}{l}\text { Within-group } \\
\text { inequality }\end{array}$ & $\begin{array}{l}\text { Between- } \\
\text { group inequal- } \\
\text { ity }\end{array}$ & $\begin{array}{l}\% \text { of between } \\
\text { group inequality }\end{array}$ \\
\hline Bread and cereals & 0.202 & 0.190 & 0.20162 & 0.00476 & 2.306 \\
\hline Fish and seafood & 0.386 & 0.362 & 0.38414 & 0.01125 & 2.845 \\
\hline Meat & 0.246 & 0.209 & 0.24339 & 0.01004 & 3.962 \\
\hline Milk, cheese, eggs & 0.210 & 0.153 & 0.20666 & 0.00387 & 1.838 \\
\hline Oils and fats & 0.531 & 0.862 & 0.56428 & 0.02351 & 4.000 \\
\hline Fruit & 0.293 & 0.269 & 0.29193 & 0.00367 & 1.242 \\
\hline Vegetables & 0.273 & 0.239 & 0.27044 & 0.01291 & 4.556 \\
\hline $\begin{array}{l}\text { Sugar, jam, honey, } \\
\text { chocolate and con- } \\
\text { fectionery }\end{array}$ & 0.396 & 0.371 & 0.39422 & 0.00130 & 0.329 \\
\hline Food products n.e.c & 0.624 & 0.529 & 0.61874 & 0.00152 & 0.245 \\
\hline Coffee, tea and cocoa & 0.374 & 0.340 & 0.37153 & 0.00224 & 0.599 \\
\hline $\begin{array}{l}\text { Mineral water, soft } \\
\text { drink, fruit and } \\
\text { vegetable juices }\end{array}$ & 0.478 & 0.380 & 0.47415 & 0.00003 & 0.006 \\
\hline
\end{tabular}

food poverty and malnutrition according to socio-economic status, in which the largest part of total inequalities is explained by the within component (Lukwa et al., 2020).

Secondly, the same analysis and decomposition was carried out by pinpointing the inequalities between FIHs and non-FIH.

Table 7 highlights the differences between food secure and food insecure households in which we observed an increase in the inequalities observed between the two groups, especially regarding meat, oils and vegetables consumption. Globally, the share of inequalities attributable to differences between the two groups amounted to almost 5\%, which proved to be much higher than the differences found between food poor and non-food poor households.

\section{Concluding Remarks}

In recent years, several major drivers have hindered global effort to end world hunger and malnutrition in all its forms by 2030 (FAO, 2021) due to the increase of challenges caused by the COVID-19 pandemic and related containment measures.

From a policy perspective, new estimates are required on poverty measures and the cost and affordability of healthy diets, which provide an important link between food security, nutrition indicators and the analysis of their trends.

Developed countries have achieved important hunger and malnutrition goals, yet strong differences within countries still exist concerning the quality of dietary regimes and the pressure that food expenditure places on poor households. In fact, if the food expenditure share is high, few resources will remain for housing, health, leisure, and other basic needs. The aim of our study was to propose a consumption-based analytical approach to estimate the at risk of food poverty (ARoFP) rate and food insecurity index while studying the inequalities between poor and non-poor households. 
Using these original measures and the HBS data, we carried out a regional and provincial analysis in Italy.

On observing the distribution of the ARoFP among the regions, food poverty appears to be widespread among Italian regions and is not only concentrated in the Southern regions as could be expected considering the existing North-South divide in Italy. This evidence is also confirmed by the analysis at provincial levels, presenting the incidence of food poverty as a widespread phenomenon among the Italian provinces.

A key result obtained by combining ARoFP and food insecurity rates, is that $22.3 \%$ of persons are food insecure $(2.8 \%)$ or at risk of food poverty (18.7) or both $(0.8 \%)$, with Calabria, Sardegna, Molise and Marche showing the worst scenario.

On summarizing our findings and estimates, it is reasonable to state that: 1. the ARoFP rate is not geographically dependent (no north-south divide) since it is calculated by integrating the different levels of cost of living in the various regions; 2. the FIH targets very vulnerable households - higher in southern Italy; 3. the decompositions of the Theil index between sub-groups highlighted, even if at an aggregate level, the existence of differences between consumption habits and dietary choices, above all for those foods such as vegetables, whose frequent consumption is strongly required by the Mediterranean diet (Benedetti et al., 2016, 2018); 4. the proposed indicators enabled us to capture different valuable insights into topics other than absolute and relative monetary poverty, thus suggesting the need to focus future and further analyses on an integrated dimension that considers both the food poor and the food security dimensions in developed countries, as foreseen by SDGs.

It is worth noting that the proposed measures are monetary based and are therefore sensitive to intra-country price levels also if the use of regional poverty lines mitigates these price level differences. However further research is required to possibly include spatial local price levels in the proposed measures.

Future research could also involve estimating the inequalities according to type of expenditure as well as extending the proposed analytical approach to other countries and territorial systems based on similar HBS structure and design. However, appropriate estimators and corrections should be adopted in order to consider the reduced sample size that this double distinction may reveal. This will enable us to obtain insights into peculiarities of food, diet quality and consumption at sub-national level.

\section{References}

Alaimo, L. S., \& Maggino, F. (2020). Sustainable development goals indicators at territorial level: Conceptual and methodological issues-The Italian perspective. Social Indicators Research, 147(2), 383-419.

Armstrong, J., Oliveira, L., Korpi-Salmela, K., \& Lopez, J. (2019). The Integrated Phase Classification approach as an example of comprehensive system approaches. In Food security policy, evaluation and impact assessment, pp. 206-218. Routledge.

Bai, Y., Alemu, R., Block, S. A., Headey, D., \& Masters, W. A. (2021). Cost and affordability of nutritious diets at retail prices: Evidence from 177 countries. Food Policy, 99, 101983.

Beacom, E., Furey, S., Hollywood, L. E., \& Humphreys, P. (2020b). Stakeholder-informed considerations for a food poverty definition. British Food Journal.

Beacom, E., Furey, S., Hollywood, L., \& Humphreys, P. (2020a). Investigating food insecurity measurement globally to inform practice locally: a rapid evidence review. Critical Reviews in Food Science and Nutrition, pp. 1-21.

Benedetti, I., Biggeri, L., Laureti, T., \& Secondi, L. (2016). Exploring the Italians' food habits and tendency towards a sustainable diet: The Mediterranean eating pattern. Agriculture and Agricultural Science Procedia, 8, 433-440. 
Benedetti, I., Laureti, T., \& Secondi, L. (2018). Choosing a healthy and sustainable diet: A three-level approach for understanding the drivers of the Italians' dietary regime over time. Appetite, 123, 357-366.

Bertarelli, G., Biggeri, L., Giusti, C., Marchetti, S., Pratesi, M., Articus, C., Caratiola, C., Munnich, R. (2020). Methodological paper on intra-country comparisons of poverty rates, Deliverable 9.9, Leuven, H2020 InGRID-2 project, g.a. 312691.

Bidisha, S. H., Mahmood, T., \& Hossain, M. B. (2021). Assessing food poverty, vulnerability and food consumption inequality in the context of COVID-19: A case of Bangladesh. Social Indicators Research, 155(1), 187-210.

Biggeri, L., Giusti, C., Marchetti, S., \& Pratesi, M. (2018). Poverty Indicators at local level: Definitions, comparisons in real terms and small area estimation methods. Statistics and Applications, 16(1), 351-364.

Biggeri L., Pratesi M. (2017), Monetary poverty indicators at local level: definitions, methods of estimations and comparisons in real terms, Invited Paper, Proceedings of the $61^{\text {st }}$ World Statistics Congress of the International Statistical Institute, 2017, Marrakech, Morocco.

Boarini, R. and M. Mira d'Ercole (2006), "Measures of Material Deprivation in OECD Countries", OECD Social, Employment and Migration Working Papers, No. 37, OECD Publishing, Paris, https://doi.org/ $10.1787 / 866767270205$.

Brewer, M., \& O'Dea, C. (2012). Measuring living standards with income and consumption: evidence from the UK (No. 2012-05). ISER working paper series.

Campiglio, L., \& Rovati, G. (2009). Il paradosso della scarsità nell'abbondanza: il caso della povertà alimentare. Milano: Guerini and Associati.

Cantillon, B., Goedemé, T., \& Hills, J. (Eds.). (2018). Decent incomes for all: improving policies in Europe. Oxford University Press.

Carrillo-Álvarez, E., Salinas-Roca, B., Costa-Tutusaus, L., Milà-Villarroel, R., \& Shankar Krishnan, N. (2021). The measurement of food insecurity in high-income countries: A scoping review. International Journal of Environmental Research and Public Health, 18(18), 9829.

Casas-Cordero, C., Encina, J., Lahiri, P. (2016). Poverty mapping for the chilean comunas, pp. 379-403. Wiley. https://doi.org/10.1002/9781118814963.ch20.

Chaudhuri, S., \& Ravallion, M. (1994). How well do static welfare indicators identify the chronically poor? Journal of Public Economics, 53(3), 367-394.

Cowell, F. (2011). Measuring inequality. Oxford University Press.

Cowell, F. A., \& Kuga, K. (1981a). Additivity and the entropy concept: An axiomatic approach to inequality measurement. Journal of Economic Theory, 25(1), 131-143.

Cowell, F. A., \& Kuga, K. (1981b). Inequality measurement: An axiomatic approach. European Economic Review, 15(3), 287-305.

Cutillo, A., Raitano, M., \& Siciliani, I. (2020). Income-based and consumption-based measurement of absolute poverty: insights from Italy. Social Indicators Research, ppp. 1-22.

Deaton, A. (1997). The analysis of household surveys: A microeconometric approach to development policy. Johns Hopkins Press.

Eurostat (2020), Household Budget Surveys, https://ec.europa.eu/eurostat/web/household-budget-surveys/ methodology, accessed on November 4th, 2021.

FAO. (2006). Food Security. Policy Brief, June 2006, Issue 2, FAO: Rome, Italy, 2020.

FAO. (2020). The State of Food Security and Nutrition in the World 2020. Transforming Food Systems for Affordable Healthy Diets; FAO: Rome, Italy, 2020.

FAO. (2021). The State of Food Security and Nutrition in the World 2020; FAO: Rome, Italy, 2021.

Fabrizi, E., Ferrante, M. R., \& Pacei, S. (2005). Estimation of poverty indicators at sub-national level using multivariate small area models. Statistics in Transition, 7(3), 587-608.

Fabrizi, E., Ferrante, M. R., \& Trevisano, C. (2016). Bayesian beta regression models for the estimation of poverty and inequality parameters in small areas. In M. Pratesi (Ed.), Analysis of poverty data by small area estimation. Wiley.

Fay, R. E., \& Herriot, R. A. (1979). Estimation of income from small places: An application of James-Stein procedures to census data. Journal of the American Statistical Association, 74, 269-277.

Gundersen, C., Hake, M., Dewey, A., \& Engelhard, E. (2021). Food Insecurity during COVID-19. Applied Economic Perspectives and Policy, 43, 153-161.

Hadam, S., Würz, N., \& Kreutzmann, A. K. (2020). Estimating Regional Unemployment with Mobile Network Data for Functional Urban Areas in Germany. Refubium-Freie Universität Berlin Repository. https://doi.org/10.17169/refubium-26791

Healy, A. E. (2019). Measuring food poverty in Ireland: The importance of including exclusion. Irish Journal of Sociology, 27(2), 105-127. 
Hjelm, L., Mathiassen, A., \& Wadhwa, A. (2016). Measuring poverty for food security analysis: Consumption-versus asset-based approaches. Food and Nutrition Bulletin, 37(3), 275-289.

Hossain, M. B., Long, M. A., \& Stretesky, P. B. (2021). Welfare State Spending, Income Inequality and Food Insecurity in Affluent Nations: A Cross-National Examination of OECD Countries. Sustainability, 13(1), 324 .

INDDEX Project. (2018). Data4Diets: Building Blocks for Diet-related Food Security Analysis. Boston, MA: Tufts University. https://inddex.nutrition.tufts.edu/data4diets. Accessed on 4 Nov 2021.

IPC Global Partners. (2021). Integrated Food Security Phase Classification Technical Manual Version 3.1. Evidence and Standards for Better Food Security and Nutrition Decisions. Rome.

Jiang, J., Lahiri, P., Wan, S.M., Wu, C.H. (2001). "Jackknifing in the Fay-Herriot Model with an Example." In Proceedings of the seminar on funding opportunity in survey research council of professional associations on federal statistics, pp. 75-97.

Kreutzmann, A., Pannier, S., Rojas-Perilla, N., Schmid, T., Templ, M., \& Tzavidis, N. (2019). The R package emdi for estimating and mapping regionally disaggregated indicators. Journal of Statistical Software, 91(7), 1-33. https://doi.org/10.18637/jss.v091.i07

Kullback, S. (1959). Information theory and statistics. Wiley.

Loopstra, R., Reeves, A., \& Tarasuk, V. (2019). The rise of hunger among low-income households: An analysis of the risks of food insecurity between 2004 and 2016 in a population-based study of UK adults. Journal of Epidemiology and Community Health, 73(7), 668-673.

Lukwa, A. T., Siya, A., Zablon, K. N., Azam, J. M., \& Alaba, O. A. (2020). Socioeconomic inequalities in food insecurity and malnutrition among under-five children: Within and between-group inequalities in Zimbabwe. BMC Public Health, 20(1), 1-11.

Marchetti, S., \& Secondi, L. (2017). Estimates of household consumption expenditure at provincial level in italy by using small area estimation methods: "Real" comparisons using purchasing power parities. Social Indicators Research, 131(1), 215-234.

Meyer, B. D., \& Sullivan, J. X. (2011). Further results on measuring the well-being of the poor using income and consumption. Canadian Journal of Economics/revue Canadienn, 44(1), 52-87.

Moltedo, A., Troubat, N., Lokshin, M., \& Sajaia, Z. (Eds.). (2014). Analyzing food security using household survey data: Streamlined analysis with ADePT software. World Bank Publications.

Mookodi, L. (2021). Decomposition analysis of the Gini coefficient of consumer expenditures in Botswana. Development Southern Africa, 38(4), 622-642.

OECD. (2008). Growing unequal?: Income distribution and poverty in OECD countries. OECD.

OECD. (2019). “Old-age income inequality”, in Pensions at a Glance 2019: OECD and G20 Indicators. OECD Publishing.

OECD (2011). Divided we stand - Why inequality keeps rising, Paris.

Penne, T., \& Goedemé, T. (2021). Can low-income households afford a healthy diet? Insufficient income as a driver of food insecurity in Europe. Food Policy, 99, 101978.

Pereira, M., \& Oliveira, A. M. (2020). Poverty and food insecurity may increase as the threat of COVID-19 spreads. Public Health Nutrition, 23(17), 3236-3240.

Pfeffermann, D. (2013). New important developments in small area estimation. Statistical Science, 28(1), 40-68. https://doi.org/10.1214/12-STS395

Pool, U. \& Dooris, M. (2021). Prevalence of food security in the UK measured by the Food Insecurity Experience Scale. J. Public Health (Oxf). pp. 1-8.

Pratesi, M. (2016). Analysis of Poverty Data by Small Area Estimations. Wiley.

Pratesi, M., Giusti, C., \& Marchetti, S. (2013). Small area estimation of poverty indicators. Survey data collection and integration (pp. 89-101). Berlin, Heidelberg: Springer.

Rao, J.N.K. and Molina, I. (2015). Small Area Estimation, Wiley Series in Survey Methodology.

Rohde, N. (2008). Lorenz curves and generalised entropy inequality measures. Modeling income distributions and Lorenz curves (pp. 271-283). Springer.

Schmid, T., Bruckschen, F., Salvati, N., \& Zbiranski, T. (2017). Constructing sociodemographic indicators for national statistical institutes using mobile phone data: Estimating literacy rates in Senegal. Journal of the Royal Statistical Society Series A, 180(4), 1163-1190. https://doi.org/10.1111/rssa.12305

Secondi, L. (2021). Estimating Household Consumption Expenditure at Local Level In Italy: The Potential of the Cokriging Spatial Predictor. Social Indicators Research, 153(2), 651-674.

Secondi, L., Principato, L., \& Laureti, T. (2015). Household food waste behaviour in EU-27 countries: A multilevel analysis. Food Policy, 56, 25-40.

Sibrian, R. (2008). Deriving food security information from national household budget surveys: Experiences, achievements, challenges. Food and Agriculture Organization of the United Nations.

Sinha, M., \& Chaudhury, A. R. (2021). Assessing the Between-Group Inequality Through Alternative Measures of Grouping: An Indian Evidence. Social Indicators Research, pp. 1-25. 
Smith, L. C., \& Subandoro, A. (2007). Measuring food security using household expenditure surveys (Vol. 3). Intl Food Policy Res Inst.

Statistics Canada, (2007). 2005 survey of financial security - public use microdata file user guide. Statistics Canada, Ottawa. (Available from http://www.statcan.gc.ca/pub/13f0026m/13f0026m2007001-eng. html).

Stringer, R. (2016). Food security global overview. Food Poverty and Insecurity: International Food Inequalities, pp. 11-18.

Sugawasa, S., \& Kubokawa, T. (2017). Transforming Response Values in Small Area Prediction. Computational Statistics and Data Analysis, 114, 47-60. https://doi.org/10.1016/j.csda.2017.03.017

Theil, H. (1967). Economics and information theory (No. 04; HB74. M3, T4.).

UN. (2020). End poverty in all its forms everywhere, United Nations SDG1 No Poverty, available at https:// www.un.org/sustainabledevelopment/wp-content/uploads/2019/07/E_Infographic_01.pdf, accessed on November 3, 2021.

UNECE. (2017). Guide on Poverty Measurement. United Nations: New York and Geneva, 2017.

Upton, J. B., Cissé, J. D., \& Barrett, C. B. (2016). Food security as resilience: Reconciling definition and measurement. Agricultural Economics, 47(S1), 135-147.

Vilar-Compte, M., Burrola-Méndez, S., Lozano-Marrufo, A., Ferré-Eguiluz, I., Flores, D., Gaitán-Rossi, P., \& Pérez-Escamilla, R. (2021). Urban poverty and nutrition challenges associated with accessibility to a healthy diet: A global systematic literature review. International Journal for Equity in Health, 20(1), $1-19$.

Woodruff, R. S. (1952). Confidence intervals for medians and other position measures. Journal of the American Statistical Association, 57, 622-627.

World Bank. (2021). COVID-19 to Add as Many as 150 Million Extreme Poor by 2021, Press Release no: 2021/024/DEC-GPV, available at: https://www.worldbank.org/en/news/press-release/2020/10/07/ covid-19-to-add-as-many-as-150-million-extreme-poor-by-2021 [accessed on November 3, 2021]

World Food Summit (1996). Rome Declaration on World Food Security.

Zaçe, D., Di Pietro, M. L., Reali, L., de Waure, C., \& Ricciardi, W. (2021). Prevalence, socio-economic predictors and health correlates of food insecurity among Italian children-findings from a cross-sectional study. Food Security, 13(1), 13-24.

Publisher's Note Springer Nature remains neutral with regard to jurisdictional claims in published maps and institutional affiliations. 